\title{
From Psychoneuroimmunology to Immunometabolism: a New Reading for Oral Emerging Pathologies
}

\author{
Flora Ippoliti* \\ Sapienza University, Rome Italy
}

Submission: August 3, 2017; Published: August 14, 2017

*Corresponding author: Flora Ippoliti, Department of Experimental Medicine, Associate Professor, Sapienza University, Rome Italy, Email: flora.ippoliti@uniroma1.it

\section{Opinion}

Gingivitis and periodontitis are the two most common forms of oral emerging pathologies and recently the attention of researchers has focused on the relationship between abovementioned local pathologies and systemic chronic diseases. Especially several case-control and cohort studies have reported the contribution of obesity and type 2 diabetes due to their alarming spread in our western societies [1]. This evidence suggest that destructive periodontal disease is linked to obesity and metabolic syndrome, as an example of interorgan crosstalk under inflammatory conditions $[2,3]$.

Psychoneuroimmunology deals with the wide relationship between organism and the environment through the study about stress, the immune system and particularly psychosocial stress [4] often associated with a lifestyle (night work, inadequate nutrition, forced sedentary, etc.) induces, in the long term, activation of the immune system with secretion of inflammatory substances, cytokines and neuropeptides, leading to health consequences [5]. Such molecules are indispensable and useful in connecting the "periphery" to the Central Nervous System. In this way, activation of the immune response is defined as "acute neurogenic inflammation", which must have its resolution within 28-30 days. This does not happen if the stress stimulus persists and activates a chronic inflammatory response that is the source of the onset of the above-mentioned systemic pathologies [5]..

Communication between the immune system and the brain is vital for controlling inflammation by the inflammatory reflex in which afferent Vagus nerve signaling, activated by cytokines is functionally associated with efferent vagus nerve-mediated output (cholinergic anti-inflammatory pathways). Vagus nerve signaling has an important role in the regulation of feeding behaviour and metabolic homeostasis. This regulation retains energy balance and prevents fluctuations in body weight and metabolism [6,7]. The organs with high density receptors for neuropeptides, such as the lung and the intestine, are much more susceptible to stress and neurogenic inflammation. The latter is closely associated with non-myelinic fibers of sensory nerves called fibers $\mathrm{C}$ also present in the dental pulp. Its neuropeptides involved in the flogic-painful process are the substance P (SP), neurochinines A and B, somatostatin [8]. SP increases in the brain in response to numerous and different types of stress-induced psycho-social stimuli and especially in times of anxiety. Well then, all this contributes to the risk of periodontal disease for which once again inflammation is the main and common pathogenetic cause [9].

During psychological stress the brain demands extra energy from the body and a persistent cerebral energy crisis contributes to systemic malfunction.These neuroenergetic alterations promote visceral fat accumulation, subcutaneous fat loss, with subsequent dismetabolic events [10]. More and more evidence indicates that stress induces an alteration in the energy balance of our organism. In fact, some structures of the limbic system, responsible for the perception of our emotions, are connected through specific nerve pathways to the hypothalamic centers of hunger and satiety that control the daily metabolic activity, influencing its function. For the same reason, individuals suffering for stress seek pleasure from comfort food and they consume high amounts of cariogenic foods [11]. In fact they are eating too much and badly, prefer high-fat and high-carbohydrate meals that stimulate and trigger a vicious cycle leading to fat accumulation, especially visceral fat and several lines of evidence indicate that vagus nerve activity could be impaired in obesity and especially in stressed patients where the balance of the vagus / sympathetic system is completely impaired $[5,6,12]$.

Adipose tissue should be considered as an endocrine organ with high metabolic activity. Its cells, adipocytes, produce and secrete many proteins, adipokines, acting by real hormones responsible for energy regulation, and their production depends 


\section{Current Research in Diabetes \& Obesity Journal}

on the typology of adipose tissue: subcutaneous or visceral fat. Indeed, in healthy individuals the synthesis of anti-inflammatory adipokines, such as adiponectin prevails, while in stressed individuals with alterations in lean mass and fat mass, proinflammatory adipokines such as Leptin, IL-1 $\beta$ or TNF- $\alpha$ are prevalent [12]. TNF- $\alpha \_$is one of the key periodontal pathogensinduced early inflammatory cytokines in destructive periodontal disease $[3,13]$. In this regard, we recall that hypernutrition states alter the cross-talk between immune system and metabolism regulation with increased serum levels of pro-inflammatory cytokines, adipokines and other inflammatory markers.

The excess of these molecules contributes to determining that state of low chronic inflammation, which is the common denominator not only of obesity and type 2 diabetes, but also of periodontal diseases characterized by dismetabolic processes involving the alveolar bone by stimulating the formation of boneresorbing cells (osteoclasts) with degradation of the connective tissue surrounding by the metalloproteinases of the extracellular matrix which becomes an additional energy source for the activated immune system [14]. Effector T-cells and inflammatory M1 macrophages undergo active glycolysis, to quickly supply energy to carry out immune activities and proliferate; on the contrary the metabolic profile of anti-inflammatory M2 macrophages is defined by oxidative phosphorylation with lower energy consumption and higher production of ATP [15]. Since chronic activation of the immune system during stress requires metabolic energy more than physiological balance, this is consumed to the detriment of other organs and apparatus. This could explain why they become insulin resistant [5]. Indeed it is indispensable to remember that the immune system follows a rigid circadian rhythm: it activates at night when the brain and other organs are at the minimum of energy demand [16]. Studies on metabolism of immune cells have shown that metabolic processes determine immune function [17]. Therefore, so far Psychoneuroimmunology has allowed us to know the close relationship between mind and body and therefore between stressful events and illnesses, the most recent study of the chronobiology of the immune system and its metabolism, known as Immunometabolism, could help us to understand the pathogenetic association between apparently different systemic diseases and increasingly emerging oral pathologies [17].

In dendritic cells and macrophages, the switch from oxidative phosphorylation to aerobic glycolysis, triggered by immune ligands like LPS and stress metabolites as free fatty acids $[5,12]$, leads to profound immune activity changes especially release of proinflammatory cytokines [18-20].

Summing up the prolonged activation of the immune system (inflammation), due to unresolved stressful events, draws energy to the whole organism with consequent functional alterations of organs and apparatus that cause dysmetabolic systemic diseases such as obesity and type 2 diabetes, which are also associated with oral pathologies $[6,21,22]$. Based on this knowledge, in my opinion, specialists in dentistry and dental hygienists should consider not only pathogenic microbes but also and especially psychosocial stress among the causes of oral disease.

\section{References}

1. Pihlstrom BL, Michalowicz BS, Johnson NW (2005) Periodontal diseases. The Lancet 366(9499): 1809-1820.

2. Benguigui C, Bongard VJ, Ruidavetsetal JB, Chamontin B, Sixou M, et al. (2010) Metabolic syndrome, insulin resistance, and periodontitis: a cross-sectional study in a middle-aged French population. J Clin Periodontol 37(7): 601-608.

3. Khosravi R, Ka K, Huang T, Khalili S, Nguyen BH, et al. (2013) Tumor necrosis factor- $\alpha$ and interleukin-6: potential interorgan inflammatory mediators contributing to destructive periodontal disease in obesity or metabolic syndrome. Mediators Inflamm 2013: 728987.

4. AderR, Cohen N(1975) Behaviourally conditioned immunosuppression. Psychosom Med 37(4): 333-340.

5. Ippoliti F, Canitano N, Businaro R (2013) Stress and obesity as risk factors in cardiovascular diseases: a neuroimmune perspective. J Neuroimmune Pharmacol 8(1): 212-226.

6. Pavlov VA, Tracey KJ (2012) The vagus nerve and the inflammatory reflex-linking immunity and metabolism. Nat Rev Endocrinol 8(12): 743-754.

7. Chavan SS, Tracey KJ (2017) Essential Neuroscience in Immunology. J Immunol 198(9): 3389-3397.

8. Ohkubo T, Shibata M, Yamada Y, Kaya H, Takahashi H (1993) Role of substance $P$ in neurogenic inflammation in the rat incisor pulp and the lower lip. Arch Oral Biol 38(2): 151-158.

9. Muñoz M, Coveñas R (2014) Involvement of substance P and the NK-1 receptor in human pathology. Amino Acid 46(7): 1727-1750.

10. Peters A, McEwen BS, Friston K (2017) Uncertainty and stress: Why it causes diseases and how it is mastered by the brain. Prog Neurobiol.

11. Sfasciotti GL, Marini R, Pacifici A, Ierardo G, Pacifici L, et al. (2017) Childhood overweight-obesity and periodontal diseases: is there a real correlation? Ann Stomatol (Roma) 7(3): 65-72.

12. Canitano N, Paci P, Ippoliti F (2013) Emerging Role of the Fat Free Mass Preservation during Weight Loss Therapy through a Novel Advanced Bio-Impedance Device (BIA-ACC). J Obes Weight Loss Ther 3(5): 1-7.

13. Gravesand DT, Cochran D (2003) The contribution of interleukin-1 and tumor necrosis factor to periodontal tissue destruction. J Periodontol 74(3): 391-401.

14. Nascimento GG, Leite FR, Correa MB, Horta BL, Peres MA, et al. (2014) Relationship between periodontal disease and obesity: the role of lifecourse events. Braz Dent J 25(2): 87-89.

15. Geeraerts X, Bolli E, Fendt SM, Van Ginderachter JA (2017) Macrophage Metabolism As Therapeutic Target for Cancer, Atherosclerosis, and Obesity. Front Immunol 8: 289.

16. Straub RH, Cutolo M, Buttgereit F, Pongratz G (2010) Energy regulation and neuroendocrine-immune control in chronic inflammatory diseases. J Intern Med 267(6): 543-560.

17. O'Neill LA, Kishton RJ, Rathmell J (2016) A guide to immunometabolism for immunologists. Nat Rev Immunol 16(9): 553-565.

18. Kelly B, O'Neill LA (2015) Metabolic reprogramming in macrophages and dendritic cells in innate immunity. Cell Res 25(7): 771-784.

19. Krawczyk CM, Holowka T, Sun J, Blagih J, Amiel E, et al. (2010) Toll-like receptor-induced changes in glycolytic metabolism regulate dendritic cell activation. Blood 115(23): 4742-4749. 


\section{Current Research in Diabetes \& Obesity Journal}

20. Arsenault RJ, Kogut MH (2015) Immunometabolism and the Kinome Peptide Array: A New Perspective and Tool for the Study of Gut Health Front Vet Sci 2: 44.

21. Ippoliti F, Corbosiero P, Canitano N, Massoni F, Ricciardi MR, et al (2017) Work- related Stress, over-nutrition and cognitive disability. Clin Ter 168(1): 42-47.

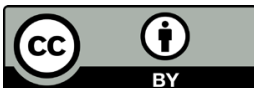

This work is licensed under Creative Commons Attribution 4.0 Licens

DOI: 10.19080/CRDOJ.2017.3.555616
22. Zoheir N, Lappin DF, Nile CJ (2012) Acetylcholine and the alpha 7 nicotinic receptor: a potential therapeutic target for the treatment of periodontal disease? Inflamm Res 61(9): 915-926.

Your next submission with Juniper Publishers will reach you the below assets

- Quality Editorial service

- Swift Peer Review

- Reprints availability

- E-prints Service

- Manuscript Podcast for convenient understanding

- Global attainment for your research

- Manuscript accessibility in different formats (Pdf, E-pub, Full Text, Audio)

- Unceasing customer service

Track the below URL for one-step submission https://juniperpublishers.com/online-submission.php 